\title{
Hypokalaemic periodic paralysis precipitated by diuretic therapy and minor surgery
}

\author{
A. J. M. Boulton \\ M.B., M.R.C.P.
}

\author{
C. A. HaRdisty \\ M.B., M.R.C.P.
}

Department of Medicine, Royal Hallamshire Hospital, Sheffield

\begin{abstract}
Summary
A case of hypokalaemic periodic paralysis was diagnosed following a severe postoperative attack in a patient whose previous episodes of weakness had been labelled hysterical. Subsequent mild attacks of weakness were precipitated by diuretic therapy. Patients with this condition should not be treated with any drug that may induce hypokalaemia.

\section{Introduction}

Hypokalaemic periodic paralysis is a rare myopathic disorder characterized by attacks of muscular weakness typically precipitated by exercise or heavy carbohydrate meals. Although usually familial, sporadic cases may occur, often in association with other conditions such as thyrotoxicosis (McArdle, 1974). A patient is now reported in whom the diagnosis of hypokalaemic periodic paralysis was made after minor surgery: prior treatment with a thiazide-like diuretic may have been contributory to the acute attack.
\end{abstract}

\section{Case report}

A 62-year-old man with mild essential hypertension was admitted for a routine nasal polypectomy. He had been taking metoprolol $150 \mathrm{mg} /$ day for 2 years and, 6 weeks before admission, xipamide $20 \mathrm{mg} /$ day had been added.

There was no other significant history, and physical examination was normal. Pre-operative investigations were normal apart from a serum potassium of $3.1 \mathrm{mmol} / 1$.

Eight hours after an uncomplicated polypectomy under a general anaesthetic, the patient complained of a generalized weakness. Although able to grip objects with his hands, he was unable to reach out for a glass or sit up in bed. Examination at this time revealed a severe proximal muscle weakness involving both the pelvic and shoulder girdle muscles. There was no sensory loss, and reflexes, although diminished, were preserved with flexor plantar responses. An electrocardiogram (ECG) taken during this acute attack showed changes typical of hypokalaemia, with prolonged PR interval of 0.24 sec, flat $T$ waves and prominent $U$ waves (Fig. 1).

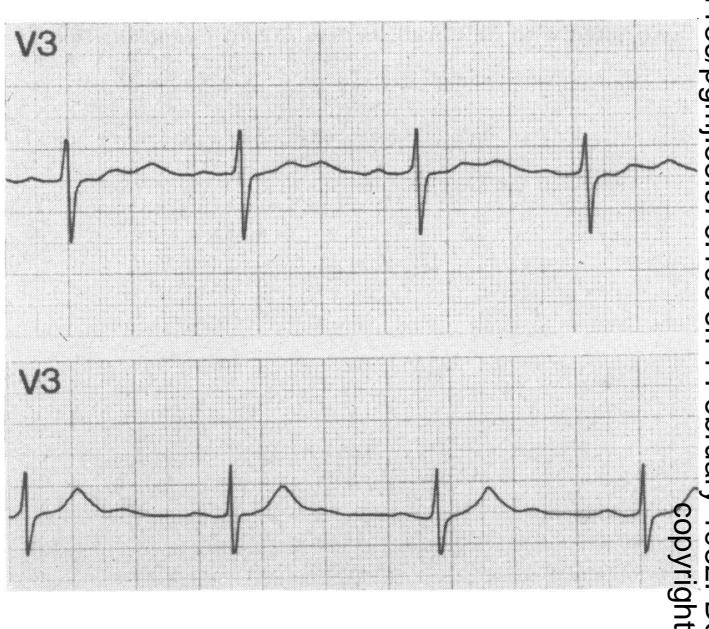

FIG. 1. ECG showing typical changes of hypokalaemia (lead V3; top trace) taken during the acute attack. Four days later (bottom trace), partial resolution of these changes has occurred.

During the attack the serum creatine kinase was $\stackrel{2}{\Rightarrow}$ elevated at $630 \mathrm{u} . / 1$ (normal $25-200 \mathrm{u} . / \mathrm{l})$, and a serum 3 potassium $24 \mathrm{hr}$ later was $3.0 \mathrm{mmol} / \mathrm{l}$. The patient admitted that he had previously experienced severato similar attacks during the last 40 years, all precipitated by heavy, unaccustomed exercise and whilst serving in the forces, these attacks had been' labelled as hysterical. A provisional diagnosis of sporadic hypokalaemic periodic paralysis was madeô and the xipamide was stopped.

Three days after operation there was no clinicalo evidence of muscle weakness and the patient was well. Before discharge, 8 days after operation, 을. serum potassium, ECG and thyroid function were all normal. A muscle biopsy from the left quadriceps. femoris, although compatible with the diagnosis, $N$ did not show the characteristic vacuoles within the N muscle fibres.

One week later he was inadvertently restarted on xipamide $20 \mathrm{mg} /$ day and he experienced 4 further mild attacks of muscle weakness over the next $\stackrel{-}{\sim}$ month, each precipitated by walking. A serum 0 potassium after the last attack was $3.4 \mathrm{mmol} / \mathrm{l}$. 
The xipamide was again withdrawn, and his hypertension controlled with metoprolol. Serum potassium on 2 subsequent occasions was $4 \cdot 2$ $\mathrm{mmol} / \mathrm{l}$ and he had no further attacks of weakness over the next 9 months.

\section{Discussion}

The diagnosis of hypokalaemic periodic paralysis in this patient was suggested by the history of exercise-induced proximal muscle weakness and confirmed both by the characteristic ECG changes of hypokalaemia during the attack and the low potassium during the recovery stage (McArdle, 1974). Although microscopy of muscle biopsy specimens during the acute attack characteristically shows vacuoles resulting from dilatation of the sarcoplasmic reticulum, these may be absent between attacks (Shy et al., 1961), as in this case. The clinical presentation of this patient was most unusual, there being few reports of the diagnosis being made postoperatively (Allely and O'Gara, 1980). That symptoms of periodic paralysis may be labelled hysterical has previously been suggested (Grotemeyer and Jörg, 1979), and the understandable reluctance of this patient to discuss his past history led to a delay in diagnosis.

It is most probable that xipamide therapy contributed to this patient's presentation as it has been suggested that patients with hypokalaemic periodic paralysis are highly susceptible to a slight fall in serum potassium concentrations (McArdle, 1974). Indeed, there is a recent case report of periodic paralysis being induced by chronic purgative abuse leading to hypokalaemia (Basser, 1979). Although xipamide is effective as an antihypertensive agent (Lentini et al., 1979) it has structural similarities to chlorthalidone and is known to cause a significant fall in serum potassium in some patients, but this change is rarely of clinical significance (Weber et al.,
1977). In this patient, not only was mild hypokalaemia present before the severe attack induced by surgery, but also when the drug was inadvertently restarted following discharge home, 4 further attacks occurred, a marked contrast to the infrequent attacks during the previous 40 years. In addition, following withdrawal of the drug, serum potassium concentrations remained normal and no further attacks have occurred.

Hypokalaemic periodic paralysis can present diagnostic problems in the immediate postoperative period, and the respiratory muscles may occasionally be affected (Grotemeyer and Jörg, 1977). Any drug causing a fall in serum potassium should be avoided in such patients.

\section{Acknowledgments}

Our thanks to Professor J. Richmond for his permission and encouragement to report this case, and to Dr W. Timperley for assessment of the muscle biopsy.

\section{References}

Allely, J.R. \& O'Gara, J.P. (1980) Postoperative hypokalemic periodic paralysis: case report. Nebraska Medical Journal, 65, 153.

BASSER, L.S. (1979) Purgatives and periodic paralysis. Medical Journal of Australia, 1, 47.

Grotemeyer, K.H. \& Jörg, J. (1979) Neue Aspekte zur paroxysmalen familiären hypokaliämischen Lähmung mit Ateminsuffizienz. Der Nervenartz, 50, 649.

Lentini, S.L., Antonelli, S., Leone, G. \& Paoletti, V. (1980) Clinical trial of xipamide in treatment of hypertension. Journal of International Medical Research, 8, 38.

MCARDLE, B. (1974) Metabolic and endocrine myopathies. In: Disorders of Voluntary Muscle, 3rd edn (Ed by Walton, J. N.), p. 726. Churchill-Livingstone, Edinburgh.

Shy, G.M., Wanko, T., Rowley, P.T. \& ENGel, A.G. (1961) Studies in familial periodic paralysis. Experimental Neurology, 3, 53.

Weber, J.C.P., Bird, H., Cash, J., Davies, P.S., Dixon, A., St J., Lister, J., Petts, H.V., Prichard, B.N.C. \& RAFTERY, E.B. (1977) Once-daily treatment of mild to moderate hypertension with xipamide: a controlled study. British Journal of Clinical Pharmacology, 4, 283. 